\title{
Application of Phenotypic and Molecular Markers to Combine Genes for Durable Resistance against Rust Virulences and High Yield Potential in Wheat
}

\author{
Muhammad Hussain $^{1 *}$, Muhammad Aslam Khan', Mumtaz Hussain ${ }^{2}$, Nazir Javed ${ }^{1}$ and Ihsan Khaliq ${ }^{3}$ \\ ${ }^{I}$ Department of Plant Pathology, University of Agriculture, Faisalabad, Pakistan \\ ${ }^{2}$ Plant Pathology Research Institute, Ayub Agricultural Research Institute, Faisalabad, Pakistan \\ ${ }^{3}$ Department of Plant Breeding and Genetics, University of Agriculture, Faisalabad, Pakistan \\ *For Correspondence: hussainwheat@yahoo.com
}

\begin{abstract}
In order to combine genes for enhancing rust resistance and high yield potential in wheat, parent lines were selected for hybridization on the basis of slow rusting history and phenotypic characters for durable resistance. The hybridized germplasm was advanced in filial generations from $F_{1}$ to $F_{5}$. Total 750 head rows were planted in $F_{6}$ from selected heads among $F_{5}$ generation. From 750 single head rows planted in Kaghan, 345 lines were selected on the basis of agronomic traits and rust resistance; two hundred and twenty lines were selected for high yield and rust resistance performance and evaluated for the presence of durable rust resistant genes with molecular markers. It was confirmed that the lines showing durable rust resistance possessed $L r 34 / Y r 18, L r 46 / Y r 29$ and $S r 2 / Y r 30$ genes in combination or individuals from these lines. The results indicated that the most prominent lines i.e., V-11211, V-11212, V-11218, V-11227, V-11262, V-11288, V-11296, V-11304, V-11308, V-11319, V-11338, V-11353, V-11365 and V-11396 showed the combination of three designated slow rusting genes. These lines were high yielding with better resistance than all existing approved wheat varieties of the country. None of these lines had complete resistance, but were of slow rusting type and were suitable for commercial cultivation. These results will be useful for wheat breeders and pathologists of the country in planning of future hybridization program. (C) 2015 Friends Science Publishers
\end{abstract}

Keywords: Breeding; Resistance; Slow rusting genes; Triticuma estivum; Leaf and stripe rust

\section{Introduction}

Wheat crop is hit by many biotic and abiotic maladies which engender to reduce its production (Jellis, 2009). Leaf rust caused by Puccinia recondita Rob. exdesm. f. sp. Tritici also called as brown rust, stripe rust caused by Puccinia striiformis Westend f. sp. tritici also called as yellow rust and stem rust caused by Puccinia graminis Pers. f. sp. tritici also called as black rust and smuts, bunts and insects particularly aphids act as biotic stresses (Hussain et al., 2006) while, terminal heat, drought, salinity, winds, hailstorms, fogs and excessive cloudy weather during crop season are the salient abiotic stresses (Hussain et al., 2011). Rusts being important worldwide are known for their ability to mutate and multiply rapidly and to use their air-borne dispersal mechanism from one field to another and even over longer distances. Rusts are currently the most important diseases of wheat worldwide, which threaten global food security (Hovmøller et al., 2010). Major wheat growing areas of the world are facing repeated severe yellow rust epidemics since 2000, when two highly aggressive and high temperature tolerant Pst strains appeared (Hovmøller et al., 2008). In Pakistan, rusts have been a constant threat to sustainable wheat production, although no severe leaf rust epidemic occurred after 1978 in the country, mainly because of release of rust resistant varieties, however, except, Inqilab-91, the average life of a variety happened to be around 5 years (Hussain et al., 1999). The reason for the early collapse of varieties is linked to the evolution of new rust races, rendering resistance in the varieties ineffective based on major genes. The latest and current trend of genetic resistance in wheat is "the resistance based on the additive effects of minor genes accumulation" (Singh et al., 1998). The durable resistance to leaf and stripe rusts of several cultivars is based on the slow rusting genes having additive effects (Singh et al., 2005). The most efficient and economical management of wheat rusts is the generation of rust resistant varieties and their on-farm cultivation (Chaudhary et al., 1998; Hussain et al., 1999; Kalappanavar et al., 2008). In the present era of scientific advancement, the wheat research is focused to 
achieve durable rust resistance through incorporation of multiple minor genes or adult plant resistance genes (Broers, 1989; Singh and Rajaram, 1991; Singh et al., 2000; Singh et al., 2005; Rehman et al., 2013). The worst yellow rust epidemics in 2005 and 2012 have wiped out major commercial wheat varieties of Pakistan (Khan et al., 2005; Hussain et al., 2015). Yellow rust (Puccinia striiformis f. sp. tritici) can reduce wheat yields by as much as $84 \%$ (Murray et al., 1995). Rusted plots yielded $4 \%$ less crops as compared to fungicide-protected plots for cultivars with hypersensitive resistance (Singh and Rajaram, 1991). Yield and kernel weight average of rusted plots are $8 \%$ less for cultivars with partial resistance, but depending on cultivar, varied from 2 to $20 \%$ less. Yield losses in wheat caused by leaf rust in cultivar trials were estimated at five locations in Mississippi from 1986 to 1989 (Khan et al., 1997). At present country is facing critical shortage of appropriate wheat varieties having both features of high yield and rust resistance to leaf, yellow and stem rust (Hussain et al., 2006). Now a days, pathologists and breeders have sought resistance mechanism based on minor genes which is called durable rust resistance or adult plant resistance (Broers, 1989; Singh and Rajaram, 1991; Singh et al., 2000). This type of rust resistance mechanism is more effective for many races rather than a single one and is long lasting (Hussain et al., 1998; Hussain et al., 1999; Bariana et al., 2001). A high level of resistance (approaching immunity) to yellow rust could be achieved by accumulating 4 to 5 minor genes in a variety (Singh et al., 2005). However, moderate level of resistance can be achieved by accumulating 2-3 minor genes in a line (Singh et al., 2005). In spite of the absence of any effective major gene, the partial resistance of varieties indicated the presence of minor genes (Hussain et al., 2006). Parents having partial resistance are crossed to pyramid genes for rust resistance and yield. This resulted many wheat lines that were better in yield and disease resistance as compared to their parent (Hussain et al., 2007). This, in addition, results in diversification of wheat genotypes in terms of their resistance background, necessary to avoid rapid evolution of the rust pathogen to acquire new virulence. Genetic resistance of leaf, yellow and stem rust resistant varieties is being considered the only remedy to prevent the crop from diseases as the long-term strategy. Hence, the objective of this study was to develop germplasm for wheat cultivars having minor gene based resistance against leaf yellow and stem rust along with characters for high yield.

\section{Materials and Methods}

The research work presented here was carried out at Wheat Research Institute (WRI) and Agriculture Biotechnology Research Institute (ABRI), Faisalabad during the year 2011-12, for the selection and molecular characterization of wheat breeding material. It involved screening of wheat germplasm against leaf and yellow rust under natural and high stress inoculation conditions for selecting the lines that may show minor gene based resistance followed by transfer of this resistance to the susceptible but high yielding varieties through conventional hybridization utilizing genotypic markers as used elsewhere for the identification of genes for pyramiding rust resistance genes in bread wheat genotypes and commercial cultivars (Khan, 1987; Dakouri et al., 2013). Newly available DNA markers X-barc 352, XWMC-44, Xgwm-533 for and Lr34/Yr18, Lr46/Yr29 and Sr2/Yr30 respectively were used to assist the selection of wheat germplasm with desirable genes (Sharp et al., 2001; Suenaga et al., 2003; William et al., 2003). Researchers have confirmed effectiveness of Lr34/Yr18, Lr46/Yr29 and Sr2/Yr30 genes against rusts (McIntosh, 1992; Singh, 1992).

\section{Selection of Breeding Material}

The material used for the crossing was selected on the basis of higher grain yield among wheat lines from the gene pool of WRI. 6-10 year rust history of the lines was also considered for final selection of the parents. Two hundred and twenty lines were selected from 750 lines for molecular characterization. The selection was based on low terminal rust reactions up to 20-30 MRMS in slow rusting response.

\section{Data Recording of Leaf and Yellow Rust}

Rusts data were recorded at every 10 days interval. The rust severity and field response were recorded according to modified Cobb's scale described by Peterson et al. (1948). Severity was recorded on the basis of percentage and field responses. Severity ratings were based upon visual observations recorded at 10 days intervals as trace to 5, 10, 20, 40, 60 and 100 percent infection and field response as immune, resistant, moderately resistant, intermediate, moderately susceptible and susceptible by the scale given in Table 1. Three observations regarding rust severity were recorded before the physical maturity of the crop. Three hundred and forty five desirable lines were selected on the basis of rust reaction. The other parameters like Plant height, Grain yield assessment ha $^{-1}$ and 1000 grain weight and protein percentage were also recorded. The disease severity data were used to calculate the area under the disease progress curve (AUDPC).

$\mathrm{AUDPC}=\Sigma \mathrm{i}[(\mathrm{xi}+\mathrm{x} \mathrm{i}+1) / 2] \mathrm{ti}$,

Where $\mathrm{xi}$ is the severity value on date $\mathrm{i}$, ti the time interval in days between two consecutive evaluations dates $i$ and $i+1$ (Chen and Line 1995a). Also the area under disease progress curve (AUDPC) was worked out by using software developed by CIMMYT (Jeger et al., 2001). The acceptable range of AUDPC for leaf rust is 300 and for yellow rust is 200 as yellow rust appears earlier in the season and can cause more losses than leaf rust. All those lines falling above these ranges were discarded out of the evaluation of resistance genes through marker application. 


\section{Molecular Characterization and Yield Testing of 220 Selected Lines Through Markers Applications}

For molecular characterization of 220 selected advanced lines for rust resistance was done by using three reliable molecular markers i.e. Xgwm-533, X-barc-352 and XWMC-44 (Sharp et al., 2001; Suenaga et al., 2003; William et al., 2003). This research work was conducted at the Agricultural Biotechnology Research Institute, AARI, Faisalabad.

\section{Sample Collection}

For DNA extraction, fresh leaves from 220 genotypes of wheat were collected from the Wheat Research Institute, Ayub Agriculture Research Institute, Faisalabad Pakistan. The fresh leaves were collected for sufficient DNA yield. After tagging of samples, the leaves were washed with distilled water and transferred in liquid nitrogen chamber available in Agricultural Biotechnology Research Institute (ABRI) and were kept on $-80^{\circ} \mathrm{C}$ for avoiding degradation of leaf samples.

\section{DNA Extraction}

Grinding was given to plant samples in liquid nitrogen to break cell walls, CTAB, was added to release DNA from the cell and nuclear membranes and chloroform was added to make DNA sample protein free. For further purification of the DNA sample, other reagents like RNase, $\mathrm{NaCl}$ are also added and centrifuged for repeated times to finally obtain DNA in the form of pellets. Before starting DNA isolation, the water bath was turned on and the temperature was set at $65^{\circ} \mathrm{C}$ and preheated $2 \mathrm{X}$ CTAB with mercaptoethanol in the water bath.

\section{Molecular Markers Analysis}

For the SSR analysis concentration of genomic DNA, 10X PCR Buffer with $\mathrm{MgCl}_{2},\left(\mathrm{NH}_{4}\right)_{2} \mathrm{SO}_{4}$, dNTPs (dATP, dCTP, dGTP, dTTP), 10mer $S S R$ primer and Taq DNA polymers were optimized. The $S S R$ primers obtained from Gene Link Company (USA) were used for the amplification of the genomic DNA. Taq Polymerase, Buffer, $\mathrm{MgCl}_{2}$ and dNTPs were purchased from Fermentas, USA. Polymerase chain reactions (PCRs) were carried out in eppendorf thermal cycler. The following concentrations of PCR reagents were used in the experiment, (Table 2). Amplification reaction profile for PCR analysis are given in Table 3-5.

\section{Protocol for Agarose Gel}

An amount of $10.5 \mathrm{~g}$ agarose was weighed in the electronic balance and dissolved in $350 \mathrm{~mL}$ 1X TBE buffer. It was heated for about $3 \mathrm{~min}$ and left to cool under running tap water. Then $15 \mu \mathrm{L}$ of ethidium bromide was added and mixed gently. The gel was poured slowly into the tank. Any bubbles were pushed away to the side using a disposable tip. The combs were inserted in it. The sizes of combs were selected according to the requirement, i.e. 23 wells, after which the gel was left to set. Having the gel solidified, the 1XTBE buffer was added to the gel tank to submerge the gel to 2-5 $\mathrm{mm}$ depth. The first well was loaded with marker/ladders with the amount of $5 \mu \mathrm{L}$. An appropriate amount of about $10 \mu \mathrm{L}+3 \mu \mathrm{L}$ dye of each sample were loaded in other wells (Table 6). The gel tank was closed and the gel was run by supplying some suitable amount of current i.e. 90 volts. After electrophoresis, the amplified products were viewed under ultraviolet transilluminator and photographed using Gene Snap software on Synvgene Gel Documentation System (GDS) USA.

\section{Results}

\section{Molecular Characterization and Yield Testing of 220 Selected Lines Through Markers Applications}

Among 220 entries under yield, 99 entries were found to be high yielding ranging from 3973-4786 kg/ha, 71 entries showed height ranging from 100 to $120 \mathrm{~cm}, 34$ entries showed higher 1000 grain weight ranging from 42 to 47 grams and 50 entries had higher protein \%, which ranged from 12-14 percentage and their rust response on the basis of AUDPC as compared to check varieties. Among 220 outstanding lines of wheat against leaf rust during the studies 137 lines exhibited AULRPC values less than 300 and rate of rust development was very slow. Only 83 entries had high levels of AULRPC rating from 325 to 950 and may be discarded in any variety development program. Similarly, among 220 outstanding lines of wheat against Yellow rust during the studies 183 genotypes exhibited AUYRPC values less than 200 and rates of rust development was also very slow. Only 37 entries had high levels of AUYRPC rating from 225 to 700 . These genotypes would be a good source for future wheat hybridization program in the country to achieve higher yield and high resistance as reported by many research workers (Ezzahiri and Roelfs, 1989; Singh, 1992; McIntosh, 1992; Maqsood et al., 2000). Among tested entries, 67 entries showed Lr34/Yr18, 23 entries showed Lr46/Yr29 and 62 entries showed $\mathrm{Sr} 2 / \mathrm{Yr} 30$ the presence. The results for identification of durable rust resistant genes were inferred on the basis of genotypic expressions (Table 8). While the rust resistance genetics were verified through amplification of molecular markers. The markers, Xgwm-533 for $\mathrm{Sr} 2 / \mathrm{Yr} 30, \mathrm{X}$-Barc352 for $L r 34 / Y r 18$ and Xwmc-44 for $L r 46 / Y r 29$ were applied to the selected 220 genotypes and the results indicated that.

Nineteen wheat genotypes showed the presence of leaf rust resistance genes $\operatorname{Lr} 34 / Y$ r 18 with the fragment size of 250 bp and only 22 advance lines were amplified by PCR in which nineteen elite lines were resistant and three V-11192, 
Table 1: Disease rating scale used to record rust severity and level of resistance/susceptibility of wheat varieties

\begin{tabular}{lll}
\hline & Field Response & Symptoms \\
\hline 0 & Immune & No visible infection \\
$\mathrm{R}$ & Resistant & Visible chlorosis or necrosis, no uredia are present \\
$\mathrm{MR}$ & Moderately Resistant & Small uredia are present and surrounded by either chlorotic or necrotic areas \\
$\mathrm{M}$ & Intermediate (Mixed) & Variable sized uredia are present some with chlorosis, necrosis or both \\
$\mathrm{MS}$ & Moderately susceptible & Medium sized uredia are present and possibly surrounded by some chlorotic areas \\
$\mathrm{S}$ & Susceptible & Large uredia are present, generally with little or no chlorosis or necrosis \\
(Peterson et al., 1948) & & \\
\hline
\end{tabular}

Table2: Concentrations and volume of reagents used in SSR markers analysis

\begin{tabular}{|c|c|c|}
\hline Reagents & Concentration & Volume \\
\hline Double distilled water $\left(\mathrm{d}_{3} \mathrm{H}_{2} \mathrm{O}\right)$ & - & 5.6 to $9.5 \mu \mathrm{L}$ \\
\hline Buffer ${ }_{\mathrm{MgCl} 2}+\left(\mathrm{NH}_{4}\right)_{2} \mathrm{SO}_{4}$ & $10 \mathrm{X}$ & 1.5 to $2.0 \mu \mathrm{L}$ \\
\hline dNTPs & $50 \mathrm{mM}$ & 0.75 to $1.50 \mu \mathrm{L}$ \\
\hline Taq Polymerase & $0.2 \mathrm{mM}$ & $3.0 \mu \mathrm{L}$ \\
\hline Primer (forward+reverse) & 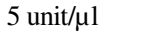 & 0.2 to $0.6 \mu \mathrm{L}$ \\
\hline Template DNA & $15 \mathrm{ng} / \mu \mathrm{l}$ & $1.5+1.5 \mu \mathrm{L}$ \\
\hline Total volume $20 \mu \mathrm{L}$ & $30 \mathrm{ng} / \mu \mathrm{l}$ & 2.0 to $5.0 \mu \mathrm{L}$ \\
\hline
\end{tabular}

Table 3: Amplification reaction profile for PCR analysis (LR34/YR18 X-BARC 352)

\begin{tabular}{lll}
\hline Steps & Temperature & Time \\
\hline $1^{\text {st }}$ & $94^{\circ} \mathrm{C}$ & 5 minutes (denaturation) \\
$2^{\text {nd }}$ & $94^{\circ} \mathrm{C}$ & 30 seconds (denaturation) \\
$3^{\text {rd }}$ & $60^{\circ} \mathrm{C}$ & 30 seconds-1 minute (annealing) \\
$4^{\text {th }}$ & $72^{\circ} \mathrm{C}$ & 30 seconds (extension) \\
$5^{\text {th }}$ & Go to $2^{\text {nd }}$ & Repeat 38 cycles \\
$6^{\text {th }}$ & $72^{\circ} \mathrm{C}$ & 5 minutes (Final extension) \\
$7^{\text {th }}$ & $20^{\circ} \mathrm{C}$ & Hold until the tubes are removed \\
\hline
\end{tabular}

Table 4: Amplification reaction profile for PCR Analysis (LR46/YR29 Xwmc-44)

\begin{tabular}{lll}
\hline Steps & Temperature & Time \\
\hline $1^{\text {st }}$ & $94^{\circ} \mathrm{C}$ & 5 minutes (denaturation) \\
$2^{\text {nd }}$ & $94^{\circ} \mathrm{C}$ & 1 minutes (denaturation) \\
$3^{\text {rd }}$ & $55^{\circ} \mathrm{C}$ & 1 minute (annealing) \\
$4^{\text {th }}$ & $72^{\circ} \mathrm{C}$ & 2 minute (extension) \\
$5^{\text {th }}$ & Go to $2^{\text {nd }}$ & Repeat 45 cycles \\
$6^{\text {th }}$ & $72^{\circ} \mathrm{C}$ & 10 minutes (final extension) \\
$7^{\text {th }}$ & $20^{\circ} \mathrm{C}$ & Hold until the tubes are removed \\
\hline
\end{tabular}

V-11202 and V-11210 were found susceptible (Fig. 1).

Lr34/Yr18 X-barc 352: Molecular marker X-barc 352 was found to be linked with $L r 34 / Y r 18$. All wheat genotypes showed the presence of leaf rust resistance genes Lr34/Yrl8 with the fragment size of $250 \mathrm{bp}$ and PCR amplified only 21 advance lines in which all the elite lines were resistant except one V-11220 (Fig. 2).

Lr46/Yr29 XWMC-44: Molecular marker XWMC-44 showed linkage to leaf rust resistance gene $L r 46 / Y r 29$. Five elite lines were resistant and fifteen i.e. V-11191, V-11194, V-11197, V-11198 V-11199, V-11200 V-11201, V-11202, V-11203, V-11204, V-11205, V-11206, V-11207, V-11208 and V-11209, were found susceptible against $\operatorname{Lr} 46 / Y r 29$ gene with the fragment size of $242 \mathrm{bp}$ and amplification of only 20 advance lines by PCR has been illustrated (Fig. 3).

Lr46/Yr29 XWMC-44: Molecular marker XWMC-44 showed linkage to leaf rust resistance gene Lr46/Yr29. Three elite lines were resistant and seventeen i.e. V-11210, V-11212, V-11213, V-11214 V-11215, V-11216 V-11217, V-11218, V-11219, V-11220, V-11221, V-11223, V-11224, V-11225 and V-11226 were found susceptible (Fig. 4).

Sr2/Yr30 XGWM-533: Molecular marker (Xgwm533) was found to be linked to stem rust resistance gene $S r 2 / Y r 30$. All wheat genotypes showed the presence of stem rust resistance genes $\mathrm{Sr} 2 / \mathrm{Yr} 30$ with the fragment size of 120 bp. Only 22 lines were amplified by PCR (Fig. 5) in which 17 lines were resistant and five i.e. V-11191, V-11202, V$11204, \mathrm{~V}-1125$ and V-11207 were found susceptible.

Sr2/Yr30 XGWM-533: Molecular marker (Xgwm533) was found to be linked to stem rust resistance gene Sr2/Yr30. All wheat genotypes showed presence of Stem rust resistance genes $\mathrm{Sr} 2 / \mathrm{Yr} 30$ with the fragments size of $120 \mathrm{bp}$ and the amplification of only 22 advance lines has been illustrated (Fig. 6) in 21 lines were resistant and one V11217 was found susceptible.

It was concluded that out of 220 genotypes, only nine genotypes V-11211, V-11227, V-11288, V-11296, 11304, V-11308, V-11319, V-11353 and V-11396 showed the combination of three designated slow rusting/durable genes, along with high yield, 1000 grain weight, protein \% and plant height ranging from $(100$ to $120 \mathrm{~cm})$. This is very important combination, as it provides protection against three types of rusts $(L R, Y R$ and $S R)$, while 15 genotypes including V-11203, V11212, V-11218, V-11223, V-11245, V-11248, V-11250, V-11262, V-11267, V-11289, V-11321, V-11232, V-11338, V-11365 and V-11359 showed the combination of $S r 2 / Y r 30$ and Lr34/Yrl8. Similarly, the combination of $\operatorname{Sr} 2 / \mathrm{Yr} 30$ and $L r 46 / Y r 29$ was found in 2 genotypes including V-11190, V-11193 and the combination of $L r 46 / Y r 29$ and $L r 34 / Y r 18$ was found in 6 genotypes including V-11276, V-11247, V-11313, V11345, V-11376 and V-11380 (Table 9).

\section{Discussion}

Among the tested genotypes, V-11211, V-11212, V-11218, V-11227, V-11262, V-11288, V-11296, V-11304, V-11308, V-11319, V-11338, V-11353, V-11365 and V-11396 showed the combination of three designated slow rusting/durable genes; Sr2/Yr30, Lr46/Yr29 and Lr34/Yrl8, 
Table 5: Amplification reaction profile for PCR analysis (SR2/YR30 Xgwm-533)

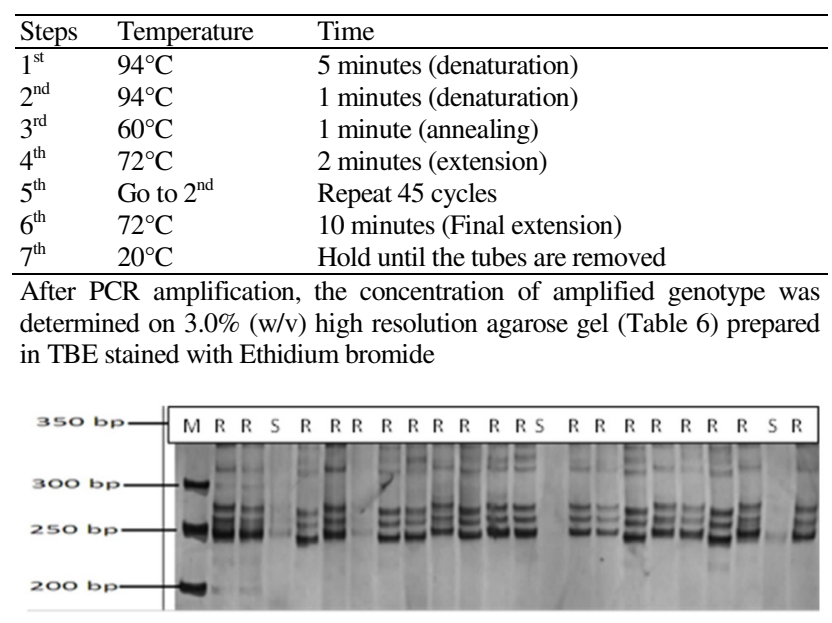

Fig. 1: PCR amplification products resolved in polyacrylamide gels using for 220 lines from elite material which produced resistant and susceptible bands by the size marker (X-barc 352)

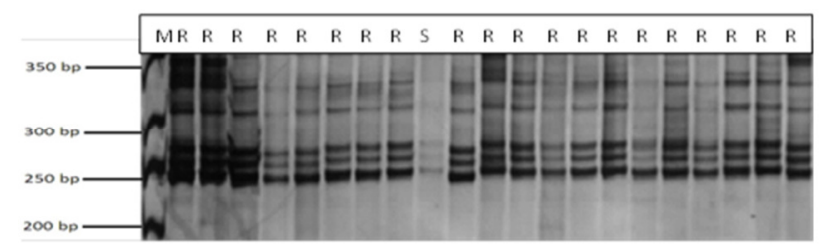

Fig. 2: PCR amplification in polyacrylamide gels when using X-barc 352 on 220 lines from elite material which produced resistant and susceptible fragments by the size marker (X-barc 352)

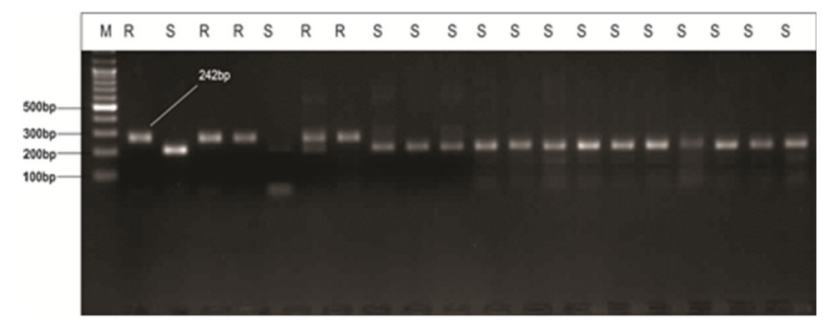

Fig. 3: PCR amplification products resolved in acrylamide gels using for 220 elite lines from elite material which produced resistant and susceptible bands by the size marker (XWMC-44)

along with high yield, 1000 grain weight, protein \% and plant height (ranging from 100 to $120 \mathrm{~cm}$ ) carried resistance near immunity under the severe leaf and yellow rust severity conditions. According to Singh et al. (2005) a high level of resistance (approaching immunity) to yellow rust could be achieved by accumulating 4 to 5 minor genes in a variety. However, moderate level of resistance can be achieved by accumulating 2-3 minor genes in a line (Singh et al., 2005). CIMMYT and AARI planned a strategy of pyramiding APR genes alone or in combination with major genes to combat the recently emerged races of stem and yellow rust (Rehman et al., 2013). These lines may be a valuable source of rust resistance with amber grain color. The resistance in the derived lines seems to be race non-specific and durable nature. The major genes possessed by the parents were susceptible as the individual line V-87094 had high terminal rust rating up to $80 \%$ in the rust screening nurseries and variety Era exhibited 10-20\% rust rating. Combinations form these parents against the prevalent leaf and yellow rust races showed fairly very low rust intensity in the country (Hussain et al., 2006). The lines which possessed major genes individually are susceptible for most rust virulences in Pakistan. Although the rust development was slow in case of $L r 34$, but alone this gene did not give desired protection and terminal rust rating was more than $60 \%$. The better resistance in the derivatives from these crosses was most probably through the pyramiding of additional minor genes in their ancestors (Hussain et al., 2010; Hussain et al., 2011). Most of the lines were resistant to moderately resistant to leaf and yellow rust under high leaf and yellow rust inoculums pressure, developed artificially at the WRI, Faisalabad. The spreader rows of susceptible Morocco were full of rust rating $80-100 \mathrm{SN}$ and there was no chance of escape. The year 2012 was the worst epidemic year for yellow rust, wiped out most of the wheat cultivars of the country including Seher-2006, MH-97 and Bakhar-2002. Only Faisalabad-2008, Lasani-2008, AARI-11, Millat-11 and $\mathrm{Pb}-11$ were found relatively resistant (Hussain et al., 2015). Therefore, a mechanism based on the additive effects of partial resistance minor genes and probably different from all the existing wheat varieties of Pakistan would be useful in breeding against rust resistance. This kind of resistance is desirable, as it is long lasting, more durable against changing rust virulence patterns. This is evidently supported by the consistent resistance response of the varieties Frontana and Era in Pakistan for the last twenty years (Hussain et al., 1999) and hence high economic returns may be achieved from such kind of resistance. Such findings and ideas have been emphasized, entrusted and floated by many researchers (Chaudhary et al., 1998; Singh et al., 1998, 2000; Hussain et al., 1999; Navabi et al., 2000).

Some new forms of rust virulence have been generated as a result of mutations in the nature. New rust virulence is appearing with the introduction of new wheat varieties and many wheat varieties have been banned for commercial cultivation only due to rust susceptibility against new rust virulence (Khan et al., 2002). Incorporation of more than one gene to cultivars for durable leaf rust resistance has remained the focus of the breeders to cope with the dynamic nature of the pathogen (Roelfs, 1988). To address this issue, gene postulation as well as molecular marker approach is being utilized for enhancing rust resistance mainly through identification of durable rust resistance gene and 


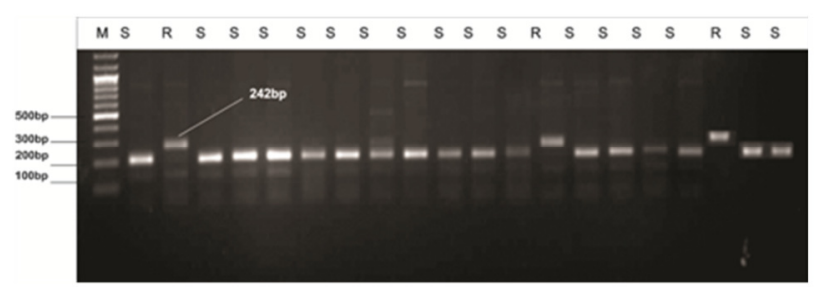

Fig. 4: PCR amplification products resolved in acrylamide gels using for 220 elitlines from elite material which produced resistant and susceptible bands by the size marker (XWMC-44)

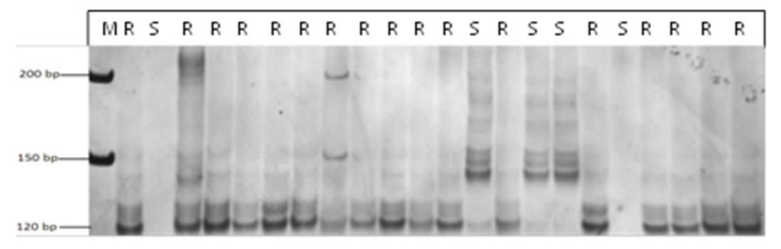

Fig. 5: PCR amplification products resolved in polyacrylamide gels when using for 220 lines of elite material which produced resistant and susceptible fragments by the size marker (Xgwm-533)

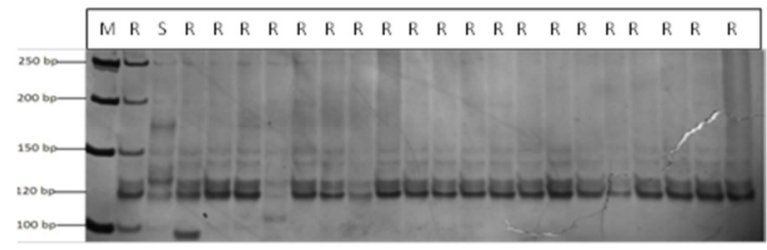

Fig. 6: PCR amplification products resolved in polyacrylamide gels when using for 220 lines of elite material which produced resistant and susceptible fragments by the size marker (Xgwm-533)

pyramiding different seedling and adult plant resistance genes. Considering this, wheat genotypes postulated to carry Lr34 gene were screened with microsatellites and STS marker (csLV34) which were found to be a useful as molecular marker and Lr34 gene were reported to be linked closely (Lagudah et al., 2006). In Pakistan, scientists postulated host material of Pakistani wheat for $L r$ family of leaf rust resistance genes including Lr34 and confirmed its presence in local genetic stocks (Rattu, 2010). Also it has been examined in 39 isogenic wheat lines and 12 commercial cultivars from Pakistan at different locations and observed virulence of Lr34 (Fayyaz, 2008). In present investigation, the molecular characterization of 220 genotypes through the application of molecular markers i.e. Xgwm-533 for Sr2/Yr30, X-Barc352 for Lr34/Yrl8 and Xwmc-44 for Lr46/Yr29 revealed that 67entries showed presence of Lr34/Yr18, 23 entries showed Lr46/Yr29 while 62 entries showed Sr2/Yr30 linkage. Cultivars possessing slow rusting illustrated lower AUDPC at adult plant stage have race-nonspecific resistance as also described by
(Sandoval-Islas et al., 1998 and Singh et al., 2005). Because the durable resistance, like slow rusting and hightemperature adult plant resistance is polygenic (at least 2-3 controlling genes) as described elsewhere (Dehghani and Moghaddam, 2004), therefore, it remains successful for longer time, even if the pathogen under goes mutation. Hence, as per our findings, lines showing low frequency of disease severity with lower AUDPC values could be considered as slow rusting lines carrying durable rust resistance against $L r 34, L r 46$ and $S r 2$ virulences, which can be utilized in breeding programs. For its relative ease, specificity and efficiency, many authors have employed PCR-based DNA markers to verify presence of leaf rust resistance in wheat (Cherukuri et al., 2003; Prabhu et al., 2004; Obert et al., 2005; Lagudah et al., 2006; Dakouri et al., 2013; Mustafa et al., 2013). Also it requires no laborious means or to wait for particular plant stage to observe time bound gene expression controlling trait of interest i.e. adult plant resistance. Therefore, for further justification of leaf rust resistance estimation, Lr34 linked sequence tagged sites (STS) molecular marker (csLV34) were used to mark the presence or absence of the gene in landraces and cultivars.

A relatively smaller size amplicon of less than $100 \mathrm{bp}$ was amplified in remaining 9 genotypes which is considered as marker for susceptible allele as that revealed that a known fragment of $79 \mathrm{bp}$ (insertion in intron) is found to be linked to leaf rust susceptibility in bread wheat gene (Lagudah et al., 2006). However, when molecular data was compared with field study, we observed two sets of observations; first type included those genotypes whose molecular data for Lr34, Lr46 and Sr2 presence corresponded well with the field data i.e. performance of genotypes in the field for avirulence pattern. The genotypes that showed the presence of $250 \mathrm{bp}$ band for Lr34 exhibited moderately resistant to moderately susceptible (Shah et al., 2010; Priyumvada et $a l ., 2009)$. Similarly the genotypes which failed to show the presence of $250 \mathrm{bp}$ band for $\mathrm{Lr} 34$ gene and were susceptible to leaf rust in the field. Hence, the absence of this gene as revealed through marker data corresponded well with the expression data in the field (Lagudha et al., 2006).

In the second category of observation both the data sets did not match with each other i.e. some of the genotypes showed the presence of Lr34 in the molecular analysis but in the field they remained susceptible to leaf rust. This contrast in the experimental and field results may be due to random mutations, suppression or deletion or evolution of new pathotype could also be the possible reason of inability of the wheat lines to cope with the avirulences (Awan et al., 2007; Dakouri et al, 2013). Some of the genotypes did not reveal the presence of Lr34 locus when screened through molecular marker although in the field those lines exhibited moderate resistance to leaf rust. These type of discrepancies have been reported in the recent past, presence of Lr34was indicated in popular wheat cultivars "Cappelle Desprez" on the basis of observed genetic association of leaf and stripe rust 
Breeding for durable resistance against Leaf and stripe rust / Int. J. Agric. Biol., Vol. 17, No. 3, 2015

Table 6: Preparation of $0.8 \%$ agarose gel

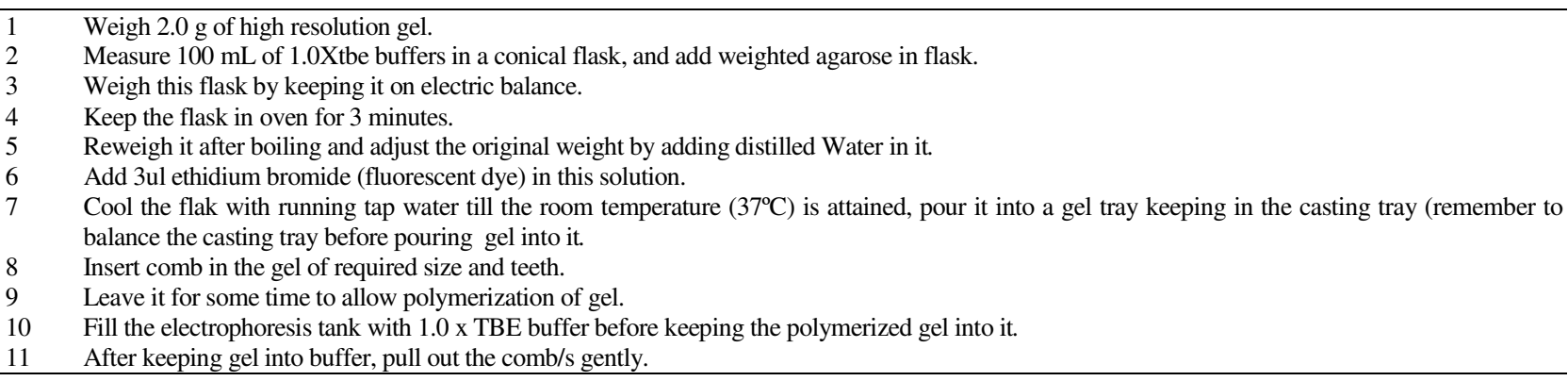

Table 7: Selection of single headlines from $\mathrm{F}_{6}$ generation crosses

\begin{tabular}{|c|c|c|}
\hline Name of the cross & Tested entries & Selected entries \\
\hline $\begin{array}{l}\text { FRT/SA42//PRL/SA42/4/Pfau/SERI.1B//Ammad/3/Waxwing } \\
\end{array}$ & 20 & 12 \\
\hline FRT/SA42//PRL/SA42/3/Wblli2*/Brambling & 22 & 13 \\
\hline FRT/SA42//PRL/SA42/3/Kiritati & 24 & 16 \\
\hline Wattan/2*ERA/2/Pak-81/2*Wattan/3/Shafaq-06/4/Brambling & 37 & 24 \\
\hline Wattan/2*ERA/2/Pak-81/2* Wattan /3/Shafaq-06/3/Wblli/ Brambling & 21 & 12 \\
\hline Wattan /Fsd-08//Kiritati & 29 & 12 \\
\hline Pak-81 2*/Wattan//2*Shafaq-06/3/Kiritati & 35 & 16 \\
\hline Pak-81 2*/Wattan//2*Shafaq-06/3/Juchi F2000 & 21 & 7 \\
\hline Pak-81 2*/Wattan//2*Shafaq-06/3/Dollarbird & 24 & 9 \\
\hline Pak-81 2*/Wattan//2*Shafaq-06/3/Kambi/2*Khawaki & 23 & 6 \\
\hline Luan/Kohistan/Pak81/3/Kiritati & 42 & 24 \\
\hline Wattan/2*ERA/2/Pak-81/2*Wattan/3/Shafaq-06/4/Kiritati & 26 & 14 \\
\hline Wattan/2*ERA/2/Pak-81/2*Wattan/3/Shafaq-06/4/Kingbird & 22 & 6 \\
\hline SH88/90A204//MH-97/3//PRL/2*Pastor & 20 & 9 \\
\hline Wattan/2*ERA//Lasani-08 & 22 & 12 \\
\hline Shafaq-06/ Luan// MH-97 & 34 & 19 \\
\hline Uqab-2000/ Wattan/Lr28//Yecora-70 & 37 & 22 \\
\hline SH88/ Pak-81// MH97/3/ Shafaq-06 & 27 & 16 \\
\hline Wattan/ 2*ERA// V04178 & 35 & 17 \\
\hline Wattan/2*ERA// V03007 & 42 & 14 \\
\hline Wattan/ 2*ERA// V04179 & 25 & 6 \\
\hline Wattan/2*ERA// Wattan/Lr28//Yecora-70 & 28 & 6 \\
\hline Lasani-08/Seher-06 & 38 & 10 \\
\hline Lasani-08/Iqbal-2000 & 27 & 14 \\
\hline Lr19/V02192// Shafaq-06 & 56 & 27 \\
\hline Total & 750 & 343 \\
\hline
\end{tabular}

Table 8: Genotypes showing slow rusting linkage

\begin{tabular}{|c|c|c|c|c|c|c|}
\hline \multirow{2}{*}{$\frac{\text { Genotypes }}{\text { V-Codes }}$} & \multirow[b]{2}{*}{ Total } & \multicolumn{3}{|c|}{ Geenotypic Markers } & \multicolumn{2}{|c|}{ Units of AUDPC ranging } \\
\hline & & $\begin{array}{l}\text { Lr34/Yr18 } \\
\text { (X-barc 352) }\end{array}$ & $\begin{array}{l}\text { Lr46/Yr29 } \\
(\mathrm{XWMC}-44)\end{array}$ & $\begin{array}{l}\text { Sr2/Yr30 } \\
(\mathrm{Xgwm}-533)\end{array}$ & $L r$ & $Y r$ \\
\hline $\begin{array}{l}\text { V-11195, V-11196, V11211, V11222, V-11227, V-11230, V-11231, } \\
\text { V-11288, V-11296, 11304, V-11308, V-11319 V-11353 and V-11396 }\end{array}$ & 14 & + & + & + & $0-200$ & $0-175$ \\
\hline $\begin{array}{l}\text { V-11194, V11198, V11200, V-11203, V11207, V-11208, V11209, V11212, } \\
\text { V11215, V11216, V-11218, V-11219, V-11221, V-11223, V11224, V11225, } \\
\text { V-11226, V11228, V-11229, V-11232, V-11244, V-11245, V-11248, V-11250, } \\
\text { V-11262, V-11263, V-11267, V-11270, V-11280, V11282, V-11289, V-11307, } \\
\text { V-11321, V-11328, V-11232, V-11329, V-11333, V-11337, V-11338, V-11340, } \\
\text { V-11356, V-11359, V-11367, V-11375, V-11390 and V-11392 }\end{array}$ & 46 & + & - & + & $0-325$ & $0-225$ \\
\hline V-11190 and V-11193 & 2 & - & + & + & $25-100$ & $25-200$ \\
\hline V-11276, V-11247, V-11290, V-11313, V-11345, V-11376 and V-11380 & 7 & + & + & - & $0-325$ & $0-275$ \\
\hline
\end{tabular}

resistance (McIntosh, 1992) but in a stark contrast was not observed using resistance gene specific marker (Lagudah et al., 2009). Besides, presence of other rust resistant gene(s) could also be the possible reason of plants resistance against disease as is the case of new leaf rust resistant gene (Lr67) which is almost similar in many characteristics to Lr34 (Spielmeyer et al., 2013). Also, PCR failure to amplify the particular band during amplification could be another probability of inconsistency between field and molecular marker data (Ali et al., 2007).

Determining the presence of $\mathrm{Lr} 34, \mathrm{Lr} 46$ and $\mathrm{Sr} 2$ in current cultivars can be helpful to predict the field resistance 
Hussain et al. / Int. J. Agric. Biol., Vol. 17, No. 3, 2015

Table 9: Elite lines with combination of three designated slow ruster, durable resistant genes, high in yield, grain weight, proteins percentage and height

\begin{tabular}{|c|c|c|c|c|c|c|c|c|}
\hline Selection & V-Code & Lr34/Yr18 & $L r 46 / Y r 29$ & Sr $2 / Y r 30$ & $\mathrm{~kg} / \mathrm{ha}$ & 1000 -grain wt & height in $\mathrm{cm}$ & Protein \% \\
\hline 119 & 11308 & + & + & + & 4786 & 44 & 109 & 10 \\
\hline 23 & 11212 & + & - & + & 4780 & 45 & 119 & 10 \\
\hline 73 & 11262 & + & - & + & 4749 & 34 & 113 & 10 \\
\hline 130 & 11319 & + & + & + & 4737 & 47 & 115 & 11 \\
\hline 115 & 11304 & + & + & + & 4663 & 42 & 114 & 10 \\
\hline 78 & 11267 & + & - & + & 4577 & 37 & 117 & 10 \\
\hline 31 & 11220 & - & - & + & 4035 & 39 & 113 & 11 \\
\hline 38 & 11227 & + & + & + & 4558 & 34 & 118 & 13 \\
\hline 34 & 11223 & + & - & + & 4558 & 37 & 119 & 10 \\
\hline 100 & 11289 & + & - & + & 4552 & 36 & 124 & 10 \\
\hline 176 & 11365 & + & - & + & 4550 & 41 & 112 & 10 \\
\hline 61 & 11250 & + & - & + & 4539 & 38 & 110 & 11 \\
\hline 149 & 11338 & + & - & + & 4517 & 35 & 119 & 12 \\
\hline 107 & 11296 & + & + & + & 4515 & 33 & 107 & 10 \\
\hline 56 & 11245 & + & - & + & 4502 & 40 & 120 & 12 \\
\hline 59 & 11248 & + & - & + & 4490 & 33 & 115 & 12 \\
\hline 207 & 11396 & + & + & + & 4488 & 41 & 118 & 11 \\
\hline 29 & 11218 & + & - & + & 4484 & 37 & 120 & 12 \\
\hline 99 & 11288 & + & + & + & 4453 & 37 & 124 & 12 \\
\hline 132 & 11321 & + & - & + & 4416 & 40 & 137 & 12 \\
\hline 211 & 11400 & - & - & - & 4414 & 37 & 129 & 12 \\
\hline 131 & 11320 & + & - & - & 4391 & 37 & 122 & 12 \\
\hline 32 & 11221 & + & - & + & 4360 & 44 & 113 & 10 \\
\hline 43 & 11232 & + & - & + & 4360 & 41 & 136 & 12 \\
\hline 87 & 11276 & + & + & - & 4317 & 46 & 118 & 11 \\
\hline 140 & 11329 & + & - & + & 4270 & 35 & 120 & 13 \\
\hline 170 & 11359 & + & - & + & 4270 & 38 & 111 & 13 \\
\hline 14 & 11203 & + & - & + & 4262 & 38 & 107 & 12 \\
\hline 91 & 11280 & + & - & + & 4256 & 44 & 113 & 12 \\
\hline 136 & 11325 & + & - & - & 4245 & 43 & 119 & 11 \\
\hline 201 & 11390 & + & - & + & 4241 & 41 & 109 & 10 \\
\hline 2 & 11191 & + & - & + & 4237 & 33 & 133 & 14 \\
\hline 124 & 11313 & + & + & - & 4231 & 47 & 129 & 11 \\
\hline 37 & 11226 & + & - & + & 4225 & 44 & 120 & 12 \\
\hline 70 & 11259 & - & - & + & 4218 & 33 & 103 & 9 \\
\hline 218 & 11407 & - & + & - & 4216 & 36 & 101 & 11 \\
\hline 90 & 11279 & - & + & - & 4194 & 45 & 120 & 12 \\
\hline 93 & 11282 & + & - & + & 4194 & 45 & 120 & 12 \\
\hline 4 & 11193 & - & + & + & 4175 & 31 & 110 & 12 \\
\hline 220 & 11409 & - & - & - & 4167 & 30 & 108 & 10 \\
\hline 167 & 11356 & + & - & + & 4159 & 41 & 122 & 12 \\
\hline 72 & 11261 & - & - & + & 4157 & 34 & 109 & 9 \\
\hline 88 & 11277 & - & - & - & 4157 & 36 & 110 & 12 \\
\hline 186 & 11375 & + & - & + & 4118 & 42 & 104 & 12 \\
\hline 156 & 11345 & + & + & - & 4085 & 40 & 110 & 11 \\
\hline 163 & 11352 & - & - & - & 4085 & 44 & 100 & 10 \\
\hline 135 & 11324 & + & - & - & 4072 & 36 & 117 & 12 \\
\hline 96 & 11285 & - & - & - & 4070 & 39 & 121 & 13 \\
\hline 184 & 11373 & - & - & - & 4068 & 42 & 112 & 13 \\
\hline 122 & 11311 & - & - & - & 4058 & 42 & 121 & 11 \\
\hline 92 & 11281 & - & - & + & 4046 & 44 & 137 & 11 \\
\hline 191 & 11380 & + & + & - & 4031 & 38 & 114 & 10 \\
\hline 1 & 11190 & - & + & + & 4027 & 42 & 113 & 12 \\
\hline 161 & 11350 & - & + & - & 4023 & 42 & 113 & 11 \\
\hline 169 & 11358 & - & & - & 4023 & 36 & 102 & 10 \\
\hline 187 & 11376 & + & + & - & 4019 & 38 & 102 & 11 \\
\hline 152 & 11341 & - & + & - & 3986 & 43 & 111 & 10 \\
\hline 39 & 11228 & + & - & + & 4311 & 36 & 116 & 10 \\
\hline 139 & 11328 & + & - & + & 4295 & 35 & 19 & 10 \\
\hline 140 & 11329 & + & - & + & 4270 & 34 & 120 & 13 \\
\hline 22 & 11211 & + & + & + & 4484 & 37 & 120 & 11 \\
\hline
\end{tabular}

and durability of these cultivars and to aid decisions in selecting parents for future breeding and development of new and improved cultivars with improved leaf rust resistance. Therefore, the strategy of incorporating partially resistant minor gene in wheat genotypes through hybridization is the best way to achieve long lasting resistance in the wheat cultivars under the changing pattern of rust races/virulence in the country. 


\section{Conclusion}

Nine lines i.e., V-11211, V-11227, V-11288, V-11296, V-11304, V-11308, V-11319, V-11353 and V-11396 showed the combination of three designated slow ruster/durable resistant genes $(\mathrm{Sr} 2 / \mathrm{Yr} 30, \mathrm{Lr} 46 / \mathrm{Yr} 29$ and Lr34/Yr18). Fifteen lines including V-11203, V11212, V-11218, V-11223, V-11245, V-11248, V-11250, V11262, V-11267, V-11289, V-11321, V-11232, V$11338, \mathrm{~V}-11365$ and $\mathrm{V}-11359$ showed the combination of $L r 34 / Y r 18$ and Sr2/Yr30. Two lines including V11190 , as well as V-11193 showed the combination of Lr46/Yr29 and Sr2/Yr30. Six genotypes including V11276, V-11247, V-11313, V-11345, and V-11376 and V-11380 showed combination of Lr46/Yr29 and Lr34/Yr18. These outstanding lines having high level of partial resistance along with lower AUDPC may be used in breeding program to transfer its partial/durable resistance character to the adapted wheat cultivars/varieties of Pakistan (Inqilab-91, MH-97, Wattan, Pb-96, Seher-2006 and Shafaq-2006 etc).

\section{Acknowledgement}

The authors gratefully acknowledge the support for providing research facilities by the Directors and Wheat Botanists, Wheat Research Institute and Agricultural Biotechnology Institute AARI, Faisalabad.

\section{References}

Ali, S.S., J.A. Shah, I.H. Khalil, H. Raman, K. Maqbool and W. Ullah, 2007. Partial resistance to yellow rust in introduced winter wheat germplasm at the north of Pakistan. Aus. J. Crop Sci., 3: 37-43

Awan, A.R., S.M. Mughal, Y. Iftikhar and H.Z. Khan, 2007. In vitro elimination of potato leaf roll polero virus from potato varieties. Eur. J. Sci. Res., 18: 155-164

Bariana, H.S., M.J. Hayden, N.U. Ahmad, J.A. Bell, P.J. Sharp and R.A. McIntosh, 2001. Mapping of durable adult plant and seedling resistance to stripe and stem rust disease in wheat. Aust. J. Agric. Res., 52: 1247-1255

Broers, L.H.M., 1989. Partial resistance to wheat leaf rust in 18 spring wheat cultivars. Euphytica, 44: 247-258

Chaudhary, M.H., M. Hussain, A. Sattarand and J. Ahamad, 1998 Strategies for evolution of high yielding disease resistant wheat varieties. Pak. J. Phytopathol., 10: 66-71

Cherukuri, D.P., S.K. Gupta, A. Charpe, S. Koul, K.V. Prabhu, R.B. Singh, Q.M.R. Haq and S.V.S. Chauhan, 2003. Identification of a molecular marker linked to an Agropyron elongatum derived gene $\operatorname{Lr} 19$ for leaf rust resistance in wheat. Plant. Breed., 122: 204-208

Chen, X.M. and R.F. Line, 1995a. Gene action in wheat cultivars for durable, high-temperature, adult-plant resistance and interaction with race-specific, seedling resistance to Puccinia striiformis. Phytopathology, 85: 567-572

Dakouri, A., B.D. McCallum, N. Radovanovic and S. Cloutier, 2013. Molecular and phenotypic characterization of seedling and adult plant leaf rust resistance in a world wheat collection. Mol. Breed., 32: 663-677

Dehghani, H. and M. Moghaddam, 2004. Genetic analysis of the latent period of stripe rust in wheat seedlings. J. Phytopathol., 152: 325-330

Ezzahiri, B. and A.P. Roelfs, 1989. Inheritance and expression of adult plant resistance to leaf rust in Era wheat. Plant Dis., 73: 549-551
Fayyaz, M., A.R. Rattu, I. Ahmad, M.A. Akhtar, A.A. Hakro and A.M. Kazi, 2008. Current status of the occurrence and distribution of (Puccinia triticina) wheat leaf rust virulence in Pakistan. Pak. J. Bot., 40: 887-895

Hovmøller, M.S., W. Stephanie and F.J. Annemarie, 2010. Escalating Threat of Wheat Rust Science. Vol. 5, p: 369

Hovmøller, M.S., H. Amor, E.A. Yahyaoui and F.J. Annemarie, 2008. Rapid global spread of two aggressive strains of a wheat rust fungus. Mol. Ecol., 17: 3818-3826

Hussain, M., M.H. Chaudhary, J.A. Shah, M. Hussain and M. Younus, 1998. Genetic diversity to Puccinia recondita f. sp. Tritici in 59 wheat lines. Pak. J. Phytopathol., 10: 113-121

Hussain, M., M.H. Chaudhary, A. Rehaman, J. Anwar, S.B. Khan and M. Hussain, 1999. Development of durable rust resistance in wheat. Pak. J. Phytopath., 11: 130-139

Hussain, M., N. Ahmad, F. Muhammad, A. Rehman, M. Hussain, M.A. Khan, M. Hussain and S. Ajmal, 2011. Wheat breeding for high yield potential and durable resistance against yellow rust. Pak. $J$. Phytopathol., 21: 62-70

Hussain, M., N. Ayub, S.M. Khan, M.A. Khan, F. Muhammad and M. Hussain, 2006. Pyramiding rust resistance and high yield in bread wheat. Pak. J. Phytopathol., 18: 11-21

Hussain, M., A. Rehman, M. Hussain, F. Muhammad, M. Younis, A.Q. Malokra and M. Zulkiffal, 2007. A new high yielding durable rust resistant variety Shafaq-06. Pak. J. Phytopathol., 19: 238-242

Hussain, M., L.H. Akhtar, M. Rafiq, M.Z. Aslam, A.H. Tariq, M. Aslam, M. Arshad and S. Ahmad, 2010. Mairaj-08: A new wheat (Triticum aestivum) variety released for general cultivation under normal and late planting in Punjab Province (Pakistan). Int. J. Agric. Biol., 12: 341-347

Hussain, M., M.A. Khan, M. Hussain, N. Javed and I. Khaliq, 2015. Monitoring of rust virulence pattern through avirulence/virulence formula. Arch. Phytopathol. Plant Prot., 48: 421-433

Jellis, G.J., 2009. Crop Plant Resistance to Biotic and Abiotic Factors: Combating the Pressures on Production Systems in a Changing World. Crop Plant Resistance to Biotic and Abiotic Factors: Current Potential and Future Demands. Proceedings of the $3^{\text {rd }}$ International Symposium on Plant Protection and Plant Health in Europe, pp: $15-20$

Jeger, M.J. and S.L.H. Viljanen-Rollinson, 2001. The use of the area under the disease progress curve (AUDPC) to assess quantitative disease resistance in crop cultivars. Theor. Appl. Genet., 102: 32-40

Kalappanavar, I.K., R.K. Patidar and K. srikant, 2008. Management strategies of leaf rust of wheat caused by puccinia recondita $\mathrm{f}$. Sp. Tritici rob. Ex. Desm. Karnataka J. Agric. Sci., 21: 61-64

Khan, M.A., M. Hussain, R. Din, M. Hussain, F. Muhammad and N. Ahmad, 2005. Performance of commercial wheat varieties and advance breeding lines under heavy yellow rust epidemic in Pakistan during 2005. Pak. J. Phytopathol., 17: 85-96

Khan, M.A., 1987. Wheat Variety Development and Longevity of Rust Resistance, pp: 273-284. Government of the Punjab Agriculture Department, Lahore, Pakistan

Khan, M.A., L.E. Trevathan and J.T. Robbins, 1997. Quantitative relationship between leaf rust and wheat yield in Mississippi. Plant Dis., 81: 769-772

Khan, M.A., M. Hussain, M. Hussain and M. Hussain, 2002. Wheat leaf rust (Puccinia recondita) occurrence and shifts in its virulence in Punjab and NWFP. Pak. J. Phytopathol., 14: 1-6

Lagudah, E.S., H. McFadden, R.P. Singh, J. Huerta-Espino, H.S. Bariana and W. Spielmeyer, 2006. Molecular genetic characterisation of the Lr34/Yr18 slow rusting resistance gene region in wheat. Theor. Appl. Genet., 114: 21-30

Lagudah, E.S., S.G. Krattinger, S. Herrera-Foessel, R.P. Singh, J. HuertaEspino, W. Spielmeyer, G. Brown-Guedira, L.L. Selter and B. Keller, 2009. Gene-specific markers for the wheat gene Lr34/Yr18/Pm38 which confers resistance to multiple fungal pathogens. Theor. Appl. Genet., 119: 889-898

Maqsood, M., M. UL-Hassan, M.T. Khalid and M. Ahmad, 2000. Comparative growth and yield performance of various wheat cultivars. Int. J. Agric. Biol., 2: 374-375 
McIntosh, R.A., 1992. Close genetic linkage of genes conferring adult-plant resistance to leaf rust and stripe rust in wheat. Plant Pathol., 41: $523-527$

Murray, G.M., P.J. Ellison and A. Watson, 1995. Effects of stripe rust on the wheat plant. Aust. Plant Pathol., 24: 261-270

Mustafa, G., M.M. Alam, S.U. Khan, M. Naveed and A.S. Mumtaz, 2013. Leaf rust resistance in semi dwarf wheat cultivars: a conspectus of post green revolution period in Pakistan. Pak. J. Bot., 45: 415-422

Navabi, A., R.P. Singh, J.P. Tewari1 and K.G. Briggs, 2000. Polygenic inheritance of adult plant resistance to stripe rust (Puccinia striiformis) and leaf rust (P. triticina) in spring wheat. International Symposium Durable Rust Resistance Key to Sustainable Agriculture, pp: 4-32. Nov. 28 - Dec., 1, 2000

Obert, D.E., A.K. Fritz, J.L. Moran, S. Singh, J.C. Rudd and M.A. Menz, 2005. Identification and molecular tagging of a gene from PI 289824 conferring resistance to leaf rust (Puccinia triticina) in wheat. Theor. Appl. Genet., 110: 1439-1444

Peterson, R.F., A.B. Campbell and A.E. Hannah, 1948. A diagrammatic scale for estimating rust severity on leaves and stems of cereals. Can. J. Genet. Cytol., 26: 496-500

Prabhu, K.V., S.K. Gupta, A. Charpe and S. Koul, 2004. SCAR marker tagged to the alien leaf rust resistance gene Lr19 uniquely marking the Agropyron elongatum-derived gene Lr24 in wheat: a revision. Plant. Breed., 123: 417-420

Priyumvada, R.T., M.S. Saharan, R. Chatrath, P. Siwatch and B. Mishra, 2009. STS Marker based tracking of slow rusting Lr34 gene in Indian wheat genotypes. Ind. J. Biotechnol., 8: 207-213

Rattu, A.R., I. Ahmad, R.P. Singh, M. Fayyaz, J.I. Mirza, K.A. Khanzada and M.I. Haque, 2010. Resistance to Puccinia triticina in some Pakistani wheat. Pak. J. Bot., 42: 2719-2735

Rehman, A.U., M. Sajjad, S.H. Khan and N. Ahmad, 2013. Prospects of wheat breeding for durable resistance against brown, yellow and black rust fungi. Int. J. Agric. Biol., 15: 1209-1220

Roelfs, A.P., 1988. Genetic control of phenotypes in wheat stem rust. Ann. Rev. Phytopathol., 26: 351-367

Shah, S.J.A., M. Imtiaz and S. Hussain, 2010. Phenotypic and molecular characterization of wheat for slow rusting resistance against Puccinia striiformis Westend. f. sp. tritici. J. Phytopathol., 158: 393-402
Sandoval-Islas, J.S., L.H.M. Broers, H.E. Vivar and K.S. Osada, 1998 Evaluation of quantitative resistance to yellow rust (Puccinia striiformis $f$. $s p$. hordei) in the ICARDA/CIMMYT barley breeding program. Plant. Breed., 117: 127-130

Singh, R.P., 1992. Association between gene Lr34 for leaf rust resistance and leaf tip necrosis in wheat. Crop Sci., 32: 874-878

Singh, R.P. and S. Rajaram, 1991. Resistance to puccinia recondite f. sp. tritici in 50 Mexican bread wheat cultivars. Crop Sci., 31: 1472-1479

Singh, R.P., A. Mujeeb-Kazi and J. Huerta-Espino, 1998. Lr46: a gene conferring slow rusting resistance to leaf rust in wheat Phytopathology, 88: 890-894

Singh, R.P., J. Huerta-Espino and H.M. William, 2005. Genetics and breeding for durable resistance to leaf and stripe rusts in wheat. Turk. J. Agric., 29: 121-127

Singh, R.P., J. Huerta-Espino, S. Rajaram, 2000. Achieving near-immunity to leaf rust and stripe rust in wheat by combining slow rusting resistance genes. Acta. Phytopathol. Entomol., 35: 133-139

Sharp, P.J., S. Johnston, A.G. Brown, A.M. Mclntosh, M. Pallotta, H.S Carter, S. Bariana, E.E. Khatkar, S. Lagudah, R.P. Singh, M Khairallah, R. Potter and M.G.K. Jones, 2001. Validation of molecular markers for wheat breeding. Aust. J. Agric. Res., 52: $1357-1366$

Spielmeyer, W., R. Mago, C. Wellings and M. Ayliffe, 2013. Lr67 and Lr34 rust resistance genes have much in common, they confer broad spectrum resistance to multiple pathogens in wheat. BMC Plant Biol., 13: 96

Suenaga, K., R.P. Singh, J. Huerta-Espino and H.M. William, 2003. Microsatellite markers for genes Lr34/Yr18 and other quantitative trait loci for leaf rust and stripe rust resistance in bread wheat Phytopathology, 93: 881-890

William, H.M., R.P. Singh, J. Huerta-Espino, S. Ortiz-Islas and D. Hoisington, 2003. Molecular Marker mapping of leaf rust resistance gene $L r 46$ and its association with stripe rust gene $\mathrm{Yr} 29$ in wheat. Phytopathology, 93: 153-159

(Received 05 December 2014; Accepted 11 February 2015) 